\title{
Analysis on Collaborative Innovation System of Strategic Emerging Industries
}

\author{
He Wenzhang \\ Jiujiang University School of Economics and Management, Jiujiang City, Jiangxi Province
}

Keywords: strategy; emerging industries; collaborative innovation

\begin{abstract}
Collaborative innovation of strategic emerging industries is an important way of cooperation between enterprises and rapid development of the market. Through strategic collaborative innovation, the emerging industries can strengthen the relationship with the enterprises in the same industry, share the technology and resources, and make up for the lack of technology and configuration through a scientific and effective collective cooperation model, so as to achieve a good situation to eliminate the common development of differences. Through the understanding of the important significance of the synergistic innovation of strategic emerging industries, this paper analyzes the factors that affect its formation and development, and puts forward some countermeasures to establish a strategic new industry synergistic innovation system, thus providing a healthy and fair competition platform for the emerging industries and standardizing the economic line of enterprises in the industry, in order to create a good environment for China's emerging industries.
\end{abstract}

In the early twentieth Century, China gradually increased its attention to emerging industries, and carried out strategic cooperation in the fields of biotechnology, high technology and large data. New energy and new technology are the trend of the future development of the world. The emerging industries are low carbon economic activities based on environmental protection. Through the guidance and application of scientific research results and new technologies, the products and technologies of enterprises are popularized and the specific industrial chain is formed in the market. With the increasing popularity of science and technology in today's era, the exchange and cooperation between enterprises are increasing, so the cooperative innovation model of strategic emerging industries is more conducive to the development of enterprises. The era of cooperation of many enterprises to develop a kind of scientific and technological products together with their own resources and power has come. Through collaborative innovation between enterprises, we can break through the difficulties of many technologies, shorten the cycle of product research and development, and rely on the collaborative innovation of strategic emerging industries. Enterprises can develop core technologies together with the help of external forces to carry out the innovative development path of cooperation and cooperation.

The importance of collaborative innovation in strategic emerging industries. The formation of the collaborative innovation system of strategic emerging industries requires cooperation between upstream and downstream enterprises in the industry. No matter what position the enterprise is in the industrial chain, the enterprises need to share resources with other cooperative activities and depend on each other to face the changes of the market mutually beneficial and mutually beneficial. The innovation system needs to be driven by the core innovation enterprises in one or more markets, and through the technology of the peripheral enterprises as support and remedy, the design and marketing of the products are carried out together, and the tacit understanding between the enterprises is constantly met in the management and management so as to maintain the smooth operation of the whole innovation ecosystem. In the new industry of our country, many famous industrial chain structures are included, such as the outstanding enterprises in the vertical innovation system: Datang, HUAWEI, ZTE, HOLLEY, exhibition and so on. They carry out the development of communication equipment chip and system through cooperation, quickly occupy the market share and win the trust of the consumers. In the emerging industries, there are many horizontal collaborative innovation systems, such as IBM, Motorola, apple and other companies entering into 
the computer chip market. Through the support of advanced technology and funds, a stable innovation ecosystem is built[1].

\section{The factors affecting the collaborative innovation system of strategic emerging industries.}

The interest of members in the cooperative innovation system of strategic emerging industries is an important factor affecting the results of cooperation. Each enterprise within the system should follow the common goal and carry out the unified strategic policy and management concept to the daily marketing, and the production of the capital Jin Yundong and opportunism involved in the operation. Enterprises should solve them through communication and consultation, so as to ensure the optimal allocation of the members of the system and restrict the optimal allocation through the balance of interests. Scientific and rational allocation of cooperative funds can improve the synergy and enthusiasm of the members in the innovation ecosystem, and plan the strategic objectives fairly and impartially. In order to ensure the accuracy of the market information through the exchange of technology, talents and resources, the cooperative enterprises should cooperate without reservations to ensure the accuracy of the market information and form a situation of information symmetry and strict contract between the enterprises of the system in order to ensure the successful operation of the cooperative innovation system in the strategic emerging industries.

In the cooperative innovation system of strategic emerging industries, a unified governance and decision making is usually carried out by a member company with certain strength, so as to occupy the dominant position of governance in the system. This single management mode guided by core enterprises will help the operation of the system and speed up the execution and innovation of the system, so as to ensure the speed of enterprise development. However, there are many potential risks in this cooperative model, unless the leading enterprise occupies a certain market share and leadership in the industry, otherwise the whole system may be affected by the financial crisis at any time. However, the general innovation ecosystem will adopt two governance modes: shareholder management mode and stakeholder co governance mode. Because of the weak technical ability and management decision-making ability of the enterprises in the emerging industries, they need to be managed and managed together, supervise and balance each other in the daily operation, clear each other's power and responsibility relations, eliminate the opportunistic behavior of some enterprises in the system, and then ensure the stable operation of the new ecosystem.

\section{The strategy of establishing collaborative innovation system for strategic emerging industries}

The enterprises in the collaborative innovation system of strategic emerging industries are prone to opportunistic behaviors such as power and privacy, which will cause damage to the collective through bad behavior such as intentional destruction, public rumor and omission, and then violates the original intention and goal of the participation of the enterprises in the system. Therefore, through the intervention of the external supervision department, the opportunities of violation of the internal members of the system can be reduced, and the cost of the system operation will be reduced, thus the uncertainty and instability of the enterprise in the process of collaborative innovation can be reduced. The outside supervision departments should establish a set of scientific and complete punishment mechanism through consultation with the enterprises within the collaborative innovation system of strategic emerging industries, so that all enterprises can accept the joint sanctions and protect the cooperative innovation by restricting the behavior of the enterprises. In the process of sanctions, the units and enterprises that carry out punishment should take concerted action and maintain information sharing to coordinate each other's actions. Although opportunistic behavior is difficult to be defined and found, the supervisory department should be impartially involved in the management of the members of the enterprise, and through the performance rating of the suppliers in the industrial chain and the detailed cost information of the suppliers to find the violations, and to prevent and punish them in time. Although the punishing enterprise can continue to stay in the system, it will reduce the corresponding income in the subsequent contract signing and 
the distribution of interests, and publish its illegal information in the whole industry, in order to warn other enterprises to make a strategic vision for the new industry to pay their own efforts and restrain the machine. Socialistic behavior.

The reputation of the collaborative innovation system of strategic emerging industries is very important to the development of the internal enterprises in the industry. As the new industry is more strange to the public, a good word of mouth can eliminate the conflict between the consumers and the emerging products, so it is more willing to communicate with the enterprises and show them through the enterprises. Strength and skills to improve their trustworthiness. At the same time, reputation can reduce the uncertainty of cooperative innovation system cooperation behavior, broaden the scope of marketing in the market, and then reduce the cost of advertising and other enterprises. Enterprises with good reputation can better integrate into the market of emerging industries, and can also bring more potential cooperation opportunities for enterprises. The members of the innovative ecosystem must eliminate opportunistic behavior, ensure good reputation of their own business behavior, create a good taste within the industry and the public, and attract other enterprises to cooperate with them through the free spread of the market. The reputation of the enterprise needs long-term management and maintenance, and the credibility of the collaborative innovation system requires the efforts of all members, although it takes a certain cost, but the final result will make the internal business of the system get a huge profit. Therefore, reputation is a valuable intangible asset for the collaborative innovation system of strategic emerging industries[3].

The new industry cooperative innovation system adopts the hierarchical management and decision-making model, and the enterprises with important role in the system have the right to assign priority to the interests. However, in the process of dealing with some development directions and the use of funds, negotiation and negotiation mechanisms are needed. Enterprises with stronger strength generally have strong voice. Although the enterprises in the system are enterprises with independent legal personality, it is still necessary to negotiate and negotiate between the enterprises in the decision of major projects, and finally to finalize the general strategic plan for the future development. The enterprises in the system determine the development direction of the new industry through negotiation level, and determine the manufacturing and marketing of intellectual property and basic products through the size of the bargaining power in the system, thus expanding the influence of the enterprise. The emerging industries should attach importance to the maintenance of intellectual property, so as to create the greatest benefits in the market competition, and then create considerable profits for the enterprises within the system. In the intellectual property of the same new industry, many enterprises can share the right of production through proportion, for example, in the coding technology of telecom TD, HUAWEI has occupied about $10 \%$ of the proportion of property rights and the proportion of ZTE 8\%. Through negotiation and negotiation, we can enhance the competitiveness of enterprises in the market and increase the strategic significance of the collaborative innovation system of new industries.

The benefit sharing mechanism is the basic guarantee for the stability of the new industry synergistic innovation system. The members of the war system should allocate the interests reasonably according to the degree of contribution to the organization, avoid all kinds of conflicts in the business operation as far as possible, and through negotiation and negotiation, the members of the system can accept the common interests distribution. Plan. The cooperative innovation system of emerging industries should make a fair and reasonable profit distribution agreement through the proportion of the intellectual property rights of the companies, restrict the unlawful behavior of the enterprises through the system, and balance the responsibilities, rights and obligations of the enterprises in the system. The benefit sharing mechanism is that the working procedure of the system department can be the justice and fairness of the members. The members of the new industry cooperative innovation system should be rational for their own interests, and then reduce the influence of the decision-makers on the strategic goals. The rational distribution of interests can balance the strength of the enterprises in the cooperative innovation system of the emerging industries, make the strong enterprises drive the development of the weak enterprises, and ensure 
the sharing of the resources and the application of the core technology, reduce the conflict of interests of each other, and enhance the degree of trust within the enterprise. For example, many large Internet $\mathrm{Co}$, in their business expansion, also pay attention to the protection of the interests of the upstream and downstream enterprises in the industry. In addition to the reasonable interests of small and medium supply enterprises, they should also make these enterprises participate in the cooperative innovation system of emerging industries to create an ecological circle of win-win cooperation[4].

\section{Information disclosure and platform opening mechanism}

The core value of the new industry cooperative innovation system is to share the intellectual property, skill level and customer information, adhere to the open technology platform, adhere to the open development path through two boxes, and improve the compatibility and innovation of the system through continuous cooperation and mutual help, and then attract more enterprises. Join the emerging industry collaborative innovation system, create more value, and occupy more market distribution. For example, if the same enterprises in the same industry control the operating system of their own hardware technology and are incompatible with other accessories, they can not provide a complete set of hardware and software services to the users, thereby affecting the development of each other, and the incompatible software operation is not conducive to the disclosure and opening of the information of the enterprises. In emerging industries, strategic core technology sharing can enable efficient cooperation between upstream and downstream enterprises in the collaborative innovation system of emerging industries.

Policy recommendations

The new industry cooperative innovation system should take strategic and policy oriented as the leading role, guide the development road of the enterprise by policy, realize the purpose of resource sharing and risk sharing through cooperation and mutual win mode, and establish a perfect cooperative system. The policy in the system should stipulate that the participating enterprises contribute their own technical ability and innovation consciousness, and meet the difficult appetite of the contemporary consumers through the form of brainstorming. Enterprises should coordinate policies targeted policies, formulate a series of programs, and achieve value creation through collaborative innovation[5].

China's policy on strategic emerging industries can guarantee the rationality of the internal structure, and then reduce the risk of business activities, maintain the stability and profitability of the system. The policy requires that the core enterprise, the upstream supplier and the downstream distributor in the system can conduct scientific and reasonable economic behavior, and integrate a variety of resources such as the supporting body, the industry association and the information intermediary effectively, so as to coordinate the government strategy with the root number. All kinds of opportunistic behavior of the member enterprises that can be restrained by policy can reduce the contradictions and conflicts within the system, enhance the trust among the members and improve the efficiency of the innovation ecosystem.

China's new industry cooperative innovation system should adopt the policy mode of multi-agent management, cooperate with the internal rules and regulations and national policies to optimize the allocation of resources, integrate the policy into the daily operation and management of the member enterprises, give full play to the special advantages of the new industry synergistic innovation system, and establish the macro system within the system. The cultural mechanism and collective bargaining and sanctions mechanism should not only enhance the unity of the enterprises within the system, but also promote the industrial chain to the market, improve the reputation of the new industry synergistic innovation system, create a good cooperative environment and atmosphere for the enterprises, and make a clear policy to standardize the behavior of the enterprises in the system and make a profit. To carry out the marketing and management of the enterprise for the purpose, establish the operation criterion of the process of interaction and cooperation between enterprises in a healthy and reasonable mechanism, and ensure the high quality operation of the cooperative innovation system of the emerging industries[6]. 
The establishment and improvement of the cooperative innovation system of China's strategic emerging industries plays a very important role in the development and innovation of the new industry in our country. The cooperation of enterprises can improve the efficiency of the whole system. Through understanding the importance of collaborative innovation in strategic emerging industries, this paper sums up the factors affecting the collaborative innovation system of strategic emerging industries, and puts forward the Countermeasures of the strategic emerging industry synergistic innovation system, which can help the emerging enterprises of our country be more suitable for the change of the market, and then get the sustainable development.

\section{Acknowledgements}

Foud project: Jiangxi Soft Science Research Project Funding, Project Number: 20161BBA10032) Research on the Collaborative Innovation Mechanism and Capability of New Material Enterprises along the Yangtze River Economic Belt -- Taking Jiujiang as an Example

\section{References}

[1] Qi Y, Wang J. Empirical research on collaborative innovation of strategic emerging industry based on system science[C]// International Conference on Service Systems and Service Management. IEEE, 2016:1-6.

[2] Zhang J, Jun W U. Study on Governmental Subsidy in Collaborative Innovation of Generic Technology for Strategic Emerging Industries_—Based on the Perspective of Triple Helix[J]. Journal of Changchun University, 2017.

[3] Xin J, Zhang M, Wang X. PSO and genetic algorithm optimization BP neural network contrast in collaboration innovation performance evaluation[C]// Control and Decision Conference. IEEE, 2016:4014-4018.

[4] Sun L, Miao C, Yang L. Driving Effect of Technology Innovation on Sustainable Development of Strategic Emerging Industries-Empirical Analysis based on the Nonparametric Stochastic Frontier Analysis[J]. Journal of Beijing Institute of Technology, 2017.

[5] Qiao Y, Bao Q, Li Z. Research on Civil-military Integrative Innovation and Growth of Strategic Emerging Industries under the New Normal[J]. Science \& Technology Progress \& Policy, 2016.

[6] Wang S. Business Model Innovation of Strategic Emerging Industries [J]. Forum on Science \& Technology in China, 2017.

Author information: He Wenzhang (1975.12--), male, Han nationality, Jiangxi Jiujiang people, associate professor, doctor, mainly from enterprise network organization and innovation. 